Açıköğretim Uygulamaları ve Araştırmaları Dergisi AUAd

\title{
Yükseköğretimde dijital dönüşüm
}

\author{
Okutman Eylem KORAL GÜMÜŞOĞLU \\ aAnadolu Üniversitesi, Yabancı Diller Yüksekokulu, Eskişehir, Türkiye
}

\begin{abstract}
Özet
Milenyum çağı da dediğimiz bu yüzyıl teknolojik gelişmelerin artık her alanda fazlasıyla hissedildiği bir çağdır. Son teknolojik gelişmeler hayatımızın her alanında etkili olduğu gibi eğitimde de yoğun bir şekilde kendini göstermeye başlamıştır. Yükseköğretimin de bu değişimden etkilenmesi kaçınılmazdır. Eğitimin her alanında kullanılmayan başlanan teknolojik ögelerle birlikte yükseköğretim de dijital bir dönüşüme uğramaktadır. Bu bildiride bilgi teknolojileri kullanımının yaygınlaşmasıyla değişen toplumsal istekler, öğrenen profili, öğreten profili ve kurumsal anlayış gibi ana etmenlerin dijital dönüşüme etkisi tartışlacak ve bu değişim sırasında hangi zorluklarla karşılaşabileceklerinden ve kurumların dikkat etmesi gereken öğelerden bahsedilecektedir. Son bölümde ise bütün bu etmenlerin üniversiteye olan etkisi, Türkiye'deki üniversitelerin hazır bulunuşluk seviyeleri ve Anadolu Üniversitesi'nin dijital dönüşüm seviyesi yazarın kendi düşünceleriyle tartışılacaktır.
\end{abstract}

Anahtar Sözcükler: Geleneksel Yükseköğretim, Dijital Dönüşüm, Bilgi ve İletişim Teknolojileri

\begin{abstract}
This century, Millennium age, is the century in which the technological developments are felt in every area. The latest developments in technology have started to emerge even in the education like in the other parts of our lives. It is impossible for the higher education to be able to stay away from this change. With the technological aspects used in every part of education, higher education has faced with a digital transformation. In this paper, the main aspects which have triggered a digital change in higher education like changing learner's profiles, societal needs, learner profile, teacher profile and teaching methods and the institutional aspects affected by the spreading information technologies will be discussed. Also, the challenges that a higher education can have during the digital transformation and the aspects that the higher education institutions should be careful about will be discussed in details. In the last part, the affects of all aspects on the universities, the level of readiness of the higher education in Turkey for digital transformation and Anadolu University in specific will be discussed with the writer's own thoughts.
\end{abstract}

Keywords: Traditional Higher Education, Digital Transformation, Information and Communication Technologies 


\section{Giriş}

Günümüzde toplumlar ve sosyal kurumlar bilgi çağında ortaya çıkan hızlı değişimlerle yeniden şekillenmeye başlamışlardır. Zaman değişiyor ve değişen zamanla birlikte toplumsal istekler, bireysel ihtiyaçlar ve teknoloji de gelişiyor. Son yıllarda her alanda kendini hissettiren gelişen teknoloji, üniversitelerin de ilgi odağı olmasını sağlamış ve üniversitelerin geleceği tartış1lan önemli noktalardan biri haline gelmiştir. Lenzner ve Johnson'ın (1997)'de iddia ettiği gibi büyük üniversite kampüsleri tamamen bir kalıntı haline gelip yok olmamışlardır belki ama büyük bir değişime doğru gittikleri bir gerçektir. Artık toplumun her zamandan daha fazla güncellenmiş, esnek ve işlenmeye uygun olan bilgiye ihtiyacı var. Duderstadt (2001)'ın belirttiği üzere bilgi teknolojileri insanlar ve bilgi arasındaki ilişkiyi de değiştirmiştir. Modern dijital teknolojiler o kadar hızlı gelişmiştir ki bilgi elde edinimi ve bilgiyi yönetme ve kullanma yöntemleri de o derecede hızlı değişmektedir. Bütün bu gelişmeler üniversiteler gibi bilgiyi merkez almış kurumların da değişmesine sebep olmaktadır. Üniversiteler bilgi aktarımını mekan ve zaman sınırlarından kurtaracak yeni bilgi teknolojileri kullanmaya ve hatta bunlara yenilerini eklemeye çalışmaktadırlar. Yeni bilgi teknolojilerinin öğretimin dijitalleşmesi üzerine çok yoğun etkileri bulunmaktadır.

\section{Yükseköğretimde Dijital Dönüşümün Ana Etmenleri}

\section{Toplumsal Profil}

Günümüzde bireylerin eğitimi, bilgisi ve becerileri hayat kaliteleri ve standartlarını belirleyen en önemli etmenlerden biri olmuş durumdadır. Günümüzde bireylerin hayat standartlarını arttırmak için ihtiyaçları olan eğitimi istedikleri yerde istedikleri zamanda ve istedikleri şekilde kaliteli ve karşılanabilir bir ücret ile sağlamak demokratik toplumların sorumluluğudur (Duderstadt,2001). Tabi ki de bu sorumluluktan en büyük pay yükseköğretime düşmüştür. Hayat boyu öğrenmenin de yaygınlaşmasıyla, teknoloji ile birlikte toplumun değişen eğitim ihtiyaçlarını karşılayacak daha geniş kitlelere hitap eden yeni bir eğitim sistemi ortaya çıkmaya başlamıştır. Bu yeni öğretim anlayışında geleneksel eğitimin zaman ve mekan kavramları kalmamıştır. Senkron ve asenkron öğretim araçları ve ara yüzleriyle artık eğitim "her yerde", "her zaman" ve "herkes" ile mümkündür. Duderstadt (1998)'in de belirttiği gibi modern bilgi teknolojisi bizi ve eğitim sistemimizi zaman ve mekan sınırlılıklarından özgür bırakmıştır. Toffler (1971)'in önceden de öngördüğü gibi bilgi çağı, üniversiteleri sadece geleneksel diplomalarını vermek yerine, değişimin gittikçe artan hızına ayak uyum sağlamaya 
ve hayat boyu öğrenmeye hazırlamaya zorlayacaktır. Hayat boyu öğrenme, üniversiteleri dijital dönüşüme zorlayan en önemli etkenlerden bir tanesidir. Yaşam boyu öğrenmenin amac1, bireylerin bilgi toplumuna uyum sağlamaları ve bu toplumda yaşamalarını daha iyi kontrol edebilmeleri için ekonomik ve sosyal hayatın tüm evrelerine aktif bir şekilde katılmalarına imkan vermektir (Tamer,2014). Bilgi çağının bazı gereksinimleri öğrenmenin hayat boyu olmasını neredeyse zorunlu hale getirmiştir. Longworth (2003)'de belirtildiği üzere bu gereksinimler arasında bilim ve teknolojinin bütün alanlarında sürekli olan yeni gelişmeler, internet ve bilgi teknolojilerinin kullanımı sayesinde ortaya çıkan bilgi bombardımanı, iş piyasalarının ve çalışanların daima yenilikçi ve esnek olma ihtiyaçları ve son olarak da bireyselleşmenin artması ve batı toplumlarında din ve aile yapılarının bölünmesi insanların eğitimi üniversite kampüsleriyle sınırlı tutmayıp onun dışına taşımak istemesi ve üniversite yıllarıyla sınırlamak istememelerinin en belli başlı sebeplerindendir. Çok büyük bir bilgi akışının bulunduğu günümüz bilgi çağında “ bilgi toplumun dışında başka yerlerde de meydana getirilir. Bilgi toplum ve kampüs arasında sürekli olarak değişime uğrar ve yer değiştirir” (Brown ve Duguid, 1996, s. 14). Bütün bu sebeplerden dolayı da üniversiteler kampüs dışında bulunan öğrenenlerine ulaşmak için alternatif yollar aramaya başlamışlardır. Çünkü çoğu öğrenenin zaman ve mekan kısıtlamalarından dolayı kampüs ulaşımı ya hiç yoktur ya da yok denecek kadar azdır. Bu durumda üniversiteler gelişmekte olan bilgi teknolojilerinden kendi hitap ettikleri öğrenenlerine en uygun olanlarını seçerek kampüs sınırlarını aşma ve onlara ulaşma yolunu seçmişlerdir.

\section{Öğrenci Profili}

Yükseköğretimde dijital dönüşümü neredeyse zorunlu hale getiren unsurların en önemlilerinden bir tanesi değişen öğrenci profilidir. Alanyazındaki birçok araştırmac1, yükseköğretim için en büyük değişim aracının teknoloji olduğunu ve üniversitelerin, öğrenenlerinin ve onların öğrenme yolları üzerindeki teknoloji etkisinin sonucu olarak, tarihteki en kayda değer zorluklarla karşı karşıya olduklarını savunur (Brown ve Adler 2008; Connolly, Jones ve Turner, 2006; Greenhow, Robelia ve Hughes, 2009; Kamenetz, 2010; Knight, 2009; Njenga ve Fourie, 2008).

Yeni nesil neredeyse bütün zamanlarını bilgi çağının teknolojik aletleri olan bilgisayarlar, cep telefonları, laptoplarıyla geçirmektedirler. Prensky (2001) dijital çağın bu dijital çocuklarını “ dijital yerliler” olarak tanımlamışlardır ve günümüz öğrencilerini “internet, video oyunları ve bilgisayarların dijital dillerini ana dilleri olarak konuşan" bireyler olarak görmüştür. Yeni nesil diğer bütün nesillerden farklıdır çünkü yeni nesil hayatlarının her alanına 
sinen teknolojiye sürekli maruz kalmaları sebebiyle farklı düşünüp, farklı hareket edip farklı öğreniyor. İşte tam da bu yüzden eğitim sistemi, teknolojiyi yakından takip eden bu yeni neslin ihtiyaçlarını karşılamak üzere yeniden yapılandırılmalıdır. Dijital yerliler çoklu medyayı iletişimde, aktivitelerde ve deneyimlerinde akıcı bir şekilde kullanabilen, bilgiyi tek bir kaynaktan bireysel olarak almaktansa topluluk halinde öğrenmeyi, deneyimlerini sentezlemeyi tercih eden, pasif bir öğrenme yerine deneysel ve aktif öğrenmeyi tercih eden bir öğrenen kitlesidir (Dede, 2005). Dijital yerlilerin yoğun teknoloji kullanımı sayesinde daha ilkokuldan edinmeye başladıkları ve üniversiteye kadar getirdikleri bilgi çağına has bazı beceriler vardır. Jenkins vd.,(2009) bu becerileri deneyip yanılma yoluyla problem-çözme, değişik kimlikler edinme yoluyla keşfedilen performans yeteneği, gerçek dünya uygulamaları yorumlama modelleri ile elde edilen simülasyon, çoklu-görev insanı olabilme, becerileri ve düşünce kapasitelerini geliştirebilmek için alet kullanımı, toplu zekaya sahip olma ve bir hükme varma olarak tanımlamıştır. İşte bu değişen öğrenen profilinin yükseköğretim kurumlarının üzerindeki etkileri büyüktür ve Margaryan vd.,(2010)'a göre yüksek öğretim kurumları bu gerçeği kabullenip fiziksel donanıma, teknik altyapıya ve profesyonel gelişime stratejik yatırım yaparak harekete geçmek zorundadırlar ancak böyle yapan kurumlar en iyi öğrencileri bünyesine katmak ve onlara etkili bir şekilde öğretmek konusunda dikkat çekici bir avantaj elde edeceklerdir.

\section{Öğretenin Rolü}

Tarih boyunca toplumların içinden geçtiği her türlü değişim eğitimi de direkt olarak etkilemiştir. Eğitim en önemli unsurlarından biri olan öğretmenler ve öğretim yöntemleri de eğitime paralel olarak değişikliğe uğramışlardır. Bu yeni hikayede, gerçek öğrenme sadece sınıf içerisinde, bir hoca eşliğinde, Eylül'den Temmuz'a değil de her zaman, her yerde ve arzuladığımız kişi ile gerçekleşebilir. Daha da önemlisi öğrenme, öğrenenler olarak kendimizin öğrenmeyi seçtiğimiz şeyler etrafında gerçekleşir; başkaları tarafından bize öğrenmemiz empoze edilen şeyler etrafında değil (Richardson, 2012). Tarihe baktığımızda yüzyıllardır öğretmen bilginin mutlak sahibi ve tek dağıtıcısı rolündeydi. Öğrenciler öğretmen tarafından belirlenen ve değerlendirilen öğrenme hedeflerini başarmak zorundaydılar. Öğretilmiş bilgilerin sergilenmek ve önceden verilen hazır bilgiyi ezberlemek için not gibi bazı dış kaynaklı motivasyon araçları kullanılmıştır (Lister, 2014). Diğer bir yandan Duderstadt (1997)'nin de dediği gibi dijital çağda yükseköğretim kurumlarının öğretmen olarak rollerini bir yana bırakıp öğrencilerin öğrenci deneyimlerinin, süreçlerinin ve öğrenme çevrelerinin dizaynırı olmaları gerekmektedir. Üniversiteler artık öğrencilerin kendi başına 
gerçekleştirdikleri okuma, yazma ve problem çözme becerilerini içeren öğrenme deneyimlerini bir yere bırakıp, onların arkadaşlarıyla bir araya gelerek beraber çalışıp beraber öğrendikleri ve öğretmenin de sadece onları yönlendiren bir danışman olduğu öğrenme ortamları oluşturmaya başlamak zorunda kalacaklardır. Duderstadt(1997). Dunderstadt'ın 1997'de yazdığı bu makalede ayak seslerini duyurmaya çalıştığı bu değişiklikler 21. Yüzyılda yükseköğretim kurumlarında hissedilmeye başlamıştır. Artık öğrenciler yaparak öğrenmeyi tercih etmektedirler. Bu tür bir öğrenme takım çalışması, işbirlikçi öğrenme, iletişim yeteneklerinin gelişmesini desteklemektedir. Bireysel portallar, sosyal medya, kişisel öğrenme çevreleri, teknoloji bulunuşluğu gibi etkileşimli öğrenme yöntemleri sayesinde öğrenci yeni yüzyılın gerektirdiği becerileri rahatlıkla edinebilir ve uygulama fırsatı bulabilir. Bu noktada en önemli görev teknoloji sayesinde bilgiye her an her yerde ulaşım imkanı bulan öğrencilerin öğretmenler tarafından doğru yönlendirilmesidir ( Dodd, 2015). Artık bilgi çağında öğretmen, bilginin tek sahibi ve mutlak ileticisi olmaktan çıkmış, öğrencilere doğru bilgiye ulaşmanın ya da ulaştıkları bilgiyi doğru sentezlemenin ve yönetmenin yollarını öğreten bir rehber olmuştur.

\section{Öğretim Yöntemleri}

Dijital çağda yükseköğretim kurumlarında yaşanan en önemli paradigma değişikliklerinden biri öğretim paradigmasından öğrenim paradigmasına geçiş olmasıdır. Öğretim paradigmasında bilgi öğretmen tarafından iletilir. Öğretmen bilgiyi aktarmadaki ana araçtır ve öğrenciler bu bilgiyi pasif bir şekilde sadece sınavda tekrar hatırlamak üzere alan kanallardır. Bu durumda alan bilgisine hakim her uzman iyi bir öğretmen olabilir. Öğretmen hangi bilgi parçacıklarının daha önemli olduğunu bilir ve ona göre öğretir. Oysaki öğrenim paradigmasında öğrenci öğrenme sürecindeki en önemli araçtır. Öğrenme bütünsel bir eylemdir. Bu bütünsellik öğrenci tarafından inşa edilir. Öğrenim paradigmasında öğrenme süreci ve aktiviteler öğrenci merkezlidir ve öğrenci tarafından kontrol edilir. Öğrenim paradigması, öğretim paradigmasının tersi olarak sınavlarda hazırlanılmak üzere ezberlenen parçacıklar yerine, işlevsel, bilgi tabanlı entelektüel çerçeveleri içerir (Barry ve Tagg, 1995). Diğer bir deyişle içinde bulunduğumuz bilgi çağında öğretmen merkezli sınıflardan öğrenci merkezli sınıflara geçiş olmuştur da diyebiliriz. Öğrenci merkezli bir sınıfta öğrenciler ne öğreneceklerini, nasıl öğreneceklerini ve öğrendiklerini nasıl değerlendirebileceklerini seçme özgürlüğüne sahiptirler. Öğrenci merkezli bir öğrenim öğrencilerden kendi öğrenme aktivitelerinden sorumlu olmalarını bekler ve onların içinde aktif bir biçimde bulunmasını ister Thiele, Mai ve Post (2014)' ün de belirttiği gibi teknoloji öğrenme aktivitelerini daha aktif ve daha öğrenci merkezli hale getirerek öğrenme deneyimlerini zenginleştirir. Dijital çağda 
öğretmenin sınıfı daha öğrenci merkezli hale getirebilmek için gerekli kaynaklar ve araçlar bulunmaktadır. Kitlesel açık çevrimiçi dersler, bilgisayar destekli öğrenme, etkileşimli dersler, çevrimiçi işbirlikçi öğrenme, deneysel öğrenme, harmanlanmış öğrenme gibi öğretim metotları teknolojinin derslere entegre edilerek 21. Yüzyıl becerilerinin öğrencilere öğretilmesinde yardımcı olan yöntemlerdir. Veletsianos (2010)'e göre dijital çağda, dijital uygulamalar ve bilişim teknolojileri özellikle de eğitim sektöründe hem kurumsal hem de teknolojik altyap1 sağlayarak eğitimde kullanılmaya başlanmış ve ciddi yollar katedilmiştir. Web 2.0 teknolojilerinde wikis, blogs, sosyal ağlar, youtube, twitter, e-posta, cloud gibi uygulamaların ve Web 3.0 teknolojilerinde ise ipad, laptops ve cep telefonları ile mobil öğrenmenin de hızlı bir şekilde yükseköğretim kurumlarında kullanılamaya başlanıldığı gözlenmektedir. Bu teknolojik araçlar ve kaynaklar sayesinde öğretmenler öğrenciyi müfredat seçiminden değerlendirme aşamasına kadar dersin içine aktif bir şekilde katabilir ve öğrenmeyi ömür boyu ve herkese açık hale getirebilir. Fakat Bates (2014)'ün de belirttiği üzere bu yöntemlerin sadece birini seçmek yeterli olmayacaktır. Öğrencilerin bağlamsal ilişki kurma ve uygulama, tartışma ve dönüt verme gibi becerilerini geliştirecek zengin öğrenme ortamları yaratabilmeliyiz. Tek bir öğretim metodunun, öğrencilere konu alanında bahsedilen becerileri kazanmasını sağlayacak zengin bir öğrenme ortamı yaratması pek de mümkün değildir. Ayrıca uygun teknoloji seçimi çok önemlidir. Derslerde kullanılmak üzere seçilen teknoloji dersin içeriğine ve öğretim metoduna uygun olmalıdır.

\section{Kurumsal Gereksinimler}

Yükseköğretimlerin bilgi çağının gereksinimlerine ayak uydurarak bir dijital bir değişim içine girdikleri bu dönemde Duderstadt, (2001)'in de öne sürdüğü dikkat edilmesi gereken bazı etmenler bulunmaktadır. Öncelikle eğitim kesinlikle öğrenci merkezli olmalıdır. Müfredatımız üniversitelerin ne öğretmek istediği üzerine değil de öğrencilerin ne öğrenmek üzerine kurulmalıdır. Diğer bir dikkat edilmesi gereken etmen ise eğitimin ücretidir. Artık yükseköğretim kurumlarının yüksek kalite ve düşük ücretle eğitim sunmaları istenmektedir. Dijital çağdaki teknolojik gelişmelerle bu daha çok mümkün kılınmıştır. Artık her yerden ulaşım imkanı ve zengin çoklu medya fırsatları sağlayan ve gelişmekte olan yeni internet araçlarıyla neredeyse tamamen ücretsiz bir eğitim firsatı bireylere sunulabilmektedir (Spada, 2014). Dijital çağda yükseköğretim kurumlarında kullanılan metotlar etkileşimli ve işbirlikçi olmalıdır. Zaman ve mekan kısıtlamalarını kaldıran e-senkron dersler ve tartışma forumlarıyla ve dijital çağın gereksinimlerine uygun işbirlikçi ve etkileşimli bir öğrenme ortamı sağlanabilir. 21. Yüzyılın alanında görülen çeşitlilik dijital çağda yükseköğretimin uygulaması gereken 
diğer bir etmendir. Öğrenci ihtiyaçlarının arttığı ve çeşitlendiği günümüzde kullanılan araçların ve öğretim metotlarının da ona uygun olarak çeşitli olması gerekmektedir. Son olarak kurumda kullanılan bilgi teknolojilerinin öğrencinin ihtiyaçlarını karşılayacak seviyede akıllı ve uyarlanabilir olması gerekmektedir.

Dijital dönüşümün her aşamasını teker teker planlamayıp, her etmenini ayrı ayrı değerlendirmeden tek başına teknoloji kullanımı bir üniversiteyi dijital çağın ihtiyaçlarını karşılayacak şekilde geleceğe hazırlamaz (Brown ve Duguid, 1996). "Bir yükseköğretim kurumu, teknolojinin bütün faaliyetlerine olan etkisini; daha etkileşimli, işbirlikçi ve yenilikçi öğrenme deneyimi yaşamak isteyen öğrencilerin gittikçe değişen ihtiyaçlarını; açık öğretim kaynaklarının entegre edilmesini de içeren müfredat gelişimini ve dizaynını ve teknolojiyle bağlantılı olarak değişen iş dünyası ve sanayinin gereksinimlerini” de dikkate alarak dijital dönüşüm sürecini değerlendirmelidir (Braynt, 2012, s. 3). Ayrıca üniversiteler, dijital çağda yaygın olarak kullanılan öğrenme ve öğretim deneyimlerinde teknolojik tabanlı uygulamalara sahip olmalıdırlar. Bu uygulamalar, stüdyo sınıflar, ters yüz sınıflar, yüksek kaliteli içerikler, kampüs içi ve dışı sosyal etkileşim, disiplin içi ve disiplinler arası araştırma ve sorgulama, yüksek lisans programlarının disiplinlerden ziyade problemlere odaklanarak gelişmesi, dağıtılan öğrenme yoluyla eşler arası bağlantı, yükseköğretim yoluyla sosyal ve dijital yeteneklerin artması, bütün üyelerinin sosyal ağlar yolu ile birbirine bağlı olduğu topluluk anlayışının gelişmesi ki bu toplumda öğrenenler dijital bir kimlik geliştirirler ve öğrenmeye etkileşim ve zengin ortamlı araçlarla katılırlar (Bryant,2012). Kısacası bir yükseköğretim kurumu teknolojik tabanlı dijital dönüşümü öğretim elemanı profilinden kullanılan araçlara kadar eğitim sürecinde rolü olan her etmen açısından düşünüp değerlendirmeye almalı ve uygulamalidir.

Kurumda planlama ve yönetim, uluslararası örgüt yapısı, dış etkiler, ekonomi ve fiziksel altyap1, öğrenme ve öğretme ortamları ve süreci, öğrenciye teknik ve pedagojik destek, araştırma ve proje temelli öğrenme, kütüphane ve bilgi hizmetleri yükseköğretim kurumlarının etkili bir şekilde dijitalleşmesinde önemli rol oynarlar. Kurumun bu aşamadaki kalite geliştirme sürecinde aşağıdaki konulara üzerinde stratejik eylem planı yapılmalı ve bu konular üzerinde komite çalışmaları geliştirilmelidir.

- Kaynakların planlaması ve yönetimi

- Sürdürülebilir ve katılımcı liderlik

- Öğrenenlerin ve paydaşların beklentilerinin algılanması

- Aktif öğrenme çerçevesinde programların tasarlanması, geliştirilmesi ve uygulanması

- Güven 
- Fiziksel altyap1

- Sürekli gelişimi değerlendirme

- Etkili yönetim hizmetleri (Gazi ve Aksal, 2011).

Bütün bu faktörler birbirleriyle alakalı işlenmeli ve birbirlerinden kopuk hareket etmemelidirler.

\section{Sonuç}

Yükseköğretim kurumları toplumların bir aynasıdır. Toplumdaki dengeler ve toplumun ihtiyaçlarına göre kendini uyarlayabilme esnekliğine sahip olması gerekmektedir. Esneklik belki de 21. Yüzyılda bir yükseköğretim kurumun sahip olması gereken en önemli özelliklerden birisidir. Ancak böylelikle toplumların maruz kaldığı değişsimlere ve gelişmelere uyum sağlayabilir. Bilgi çağı dediğimiz bu çağda toplumlar ve öğrenenler üzerinde en etkili olan gelişme teknolojidir. Artık hayatımızın her alanına giren teknolojinin öğrenenlerin ihtiyaçlarını belirlediği ve biçimlendirdiği çok açıktır. Ayrıca teknolojik tabanlı bir değişim sadece bireyleri ve toplumları değil, iş dünyası ve sanayinin de gereksinimlerini etkilemiş ve değiştirmiştir. Toplumda ve iş dünyasında olan bu değişimlere yükseköğretim kurumlarının tepkisiz kalması mümkün değildir. Fakat toplumun ve iş dünyasının bu isteklerine cevap vermek için dijital bir dönüşüm gereksinimine giren üniversitelerin bu değişimi sadece teknolojiyi derslerde kullanarak gerçekleştirmesi mümkün değildir. Bu konuda daha derin araştırmalar yapmalı ve alan uzmanlarından destek alarak ilerlemelidir. Yoksa bir sürü uygulama sadece kağıt üzerinde kalma tehlikesiyle karşı karşıya kalabilir. Kullanılan teknoloji de sadece kullanılmak adına öğrencilerin öğrenme hedeflerine ya da çıktılarına hiçbir katkısı olmadan derse entegre edilmemelidir. Yüz yüze geleneksel olarak dizayn edilmiş derslerden; teknolojik tabanlı, harmanlanmış ya da tamamen çevirim içi derslere geçiş her alanda bir hazır bulunuşluğu gerektirmektedir. Öğretim elemanından, kullanılan materyale, müfredattan, öğretim metoduna ve hatta kampüs içinde ki çoğu olanakların dahi teknolojik tabanlı bir dijital dönüşüme hazır olması gerekmektedir. Bu önceden yoğun bir hazırlık süreci gerekmektedir.

Üniversiteler değişime açık olmalı ve çağın arkasında kalmamalılar. Değişen toplumsal ihtiyaçlara cevap verebilmek için gerekli olan paradigma değişikliklerine hazır olmalılar. $\mathrm{Bu}$ değişimi yavaşlatacak ya da durdurabilecek her türlü yapıyı kendi içinde yok etmelidir. Değişim olacaktır bu kaçınılmaz bir gerçektir. Aksi halde çağın gereksinimlerini karşılayamayan ve toplumun ihtiyaçlarına cevap veremeyen bir yükseköğretim kurumunu çok da fazla ayakta kalması mümkün değildir. Artık üniversiteler sınırları ve ders zamanları belli bir kampüs alanı olmaktan çıkıp, insanların edindikleri bilgiyi şekillendirip, sentezledikleri ve 
ulaştıkları seviye dahilinde bunu ispat edebildikleri sertifikaları aldıkları kurumlar haline dönüşmüşlerdir. üniversiteler bütün zaman ve mekan sınırlılıklarını ortadan kaldıran senkron ve asenkron teknolojik tabanlı araçlarla eğitim hizmetini topluma ulaştırmak zorundadırlar.

\section{Öneriler}

Günümüz Türkiye'sinde de bütün dünyada olduğu gibi yükseköğretim kurumlarında bir teknoloji kullanımı görünmektedir. Fakat sadece derslerine teknoloji entegre edilmesi ile bir üniversitenin dijital dönüşüme uğradığını iddia edebilir miyiz? Sadece derslerin bir kısmında çevrimiçi alıştırmalar yapmak ya da çeşitli dijital ara yüzler kullanmakla teknolojik çağın ihtiyaçlarını karşılayabilir miyiz? Daha önce de belirtildiği üzere bu çok aşamalı bir süreçtir ve eğitimin her alanını kapsamaktadır ve dijital dönüşümünde bu her alanda uzmanlarla çalış1larak gerçekleştirilmesi gereken bir süreçtir ve bütün bu etmenler bir arada birbirleriyle uyumlu ve alakalı olarak çalışmalıdırlar. Türkiye'de yükseköğretim kurumlarına bakıldığında misyonlarında çağın gerektirdiği eğitimi sağlayacaklarına dair ifadeler bulunmaktadır. $\mathrm{Bu}$ durumda çağımızın da bilgi teknolojileri çağı olduğunu düşünürsek üniversitelerin açık ders malzemeleri, çevrimiçi dersler, uzaktan dersler gibi uygulamaları hayat geçirmeli ve bunu gerçekleştirirken de profesyonel bir şekilde alan uzmanlarıyla çalışmalı ve bu uygulamaların sadece misyonunda yazılı birkaç kelime olmaktan çıkarması gerekmektedir.

$\mathrm{Bu}$ konuda en iddialı kurumlardan biri Anadolu Üniversitesi bu işte 24. yılını tamamlamıştır ve Anadolu Üniversitesi Uzaktan Eğitim Sistemi, 1.100 bin öğrencisi ve 950 bin mezununa ulaşmıştır. Anadolu Üniversitesi Uzaktan Eğitim Sistemi ders dizaynından kullanılan materyale kadar her alanda kullanıldığı ilk andan itibaren zamanın gereksinimlerine paralel olarak kendini geliştirmiş ve çağın gereksinimlerine uygun hareket etmiştir. Teknolojik uygulamalarda yeni gelişmeler yakından takip edilmiş ve ders dizaynlarında uygulanmıştır. Tüm kitaplar ve dersler uzaktan eğitimdeki çağdaş gelişmelere uygun olarak tekrar dizayn edilmiştir. Bu sene öğrencilerin kullanımına açılan Anadolu Üniversitesi Kitlesel Açık Ders Portalı bilgi teknolojileri kullanarak toplumun hayat boyu öğrenme ihtiyaçlarına cevap veren çok önemli bir uygulamadır. Anadolu Üniversitesi'nin dijitalleşmeye çok yönlü bakması; alan yazının ve teknolojik gelişmelerin sıkı bir takipçisi olması; her alanda konu uzmanlarından oluşturduğu bir ekiple çalışıyor olması; sağlıklı ve verimli bir dijital dönüşüm sürecinden geçtiğinin göstergesidir. Diğer üniversitelerinde böyle bir süreçten geçmesi ve kendilerini değerlendirirken olaya sadece teknoloji kullanımı olarak bakmamaları ve dönüşümü bütün boyutlarıyla ele alıp uygulamaları gerekmektedir. Teknolojinin bir amaç değil, toplumun 
sürekli gelişen ve değişen eğitim ihtiyaçlarını karşılama yolunda kullanılan bir araç olduğu unutulmamalidir. 


\section{Kaynakça}

Barr, R. B. \& Tagg, J. (1995) From teaching to learning: A new paradigm for undergraduate. Change Magazine, 27(6), 12-25.

Bates, A. W. (2015). Teaching in a digital age: Guidelines for designing teaching and learning for a digital age. BC Campus: Tony Bates Associates Ltd.

Bryant, P. (2012). The modern university in the digital age. Greenwich Connect Key Documents, Educational Development Unit, University of Greenwich, London,United Kingdom.

Brown, J. S., \& Duguid, P. (1996). Universities in the digital age. Change: The Magazine of Higher Learning, 28(4), 11-19.

Brown, J.S. \& Adler, R.P. (2008). "Minds on fire' : Open education, the long tail, and learning 2.0'. Educause Review, 43(1), 16.

Connolly, M., Jones, N., \& Turner, D. (2006). EGlearning: a fresh look. Journal of Higher Education Management and Policy, 18(3), 135.

Dede, C. (2005). Planning for neomillennial learning styles. Educause Quarterly, 28(1), 7-12.

Dodd,W.D. 2015. Teaching and Learning in the Digital Age. https://webcpm.com/articles/2015/09/01/teaching-learning-technologies.aspx. 26.12.2016 tarihinde erişilmiştir.

Duderstadt, J. J. (1998). Transforming the university to serve the digital age. Cause/Effect, 20(4), 21-32.

Duderstadt, J. J. (2001). The future of the university in the digital age. Proceedings of the American Philosophical Society, 145(1), 54-72.

Gazi A., Z., Aksal A., F. (2011). Handbook of online pedagogy. Germany:LAP.

Greenhow, C., Robelia, B., \& Hughes, J.E. (2009). Learning, teaching, and scholarship in digital age. Educational Researcher, 38(4), 246-259.

Kamenetz, A. (2010). DIY U: Edupunks, edupreneurs, and the coming transformation of higher education, Chelsea Green Publishing.

Knight, S. (2009). Effective practice in a digital age, Bristol, UK: JISC Innovation Group, University of Bristol.

Lenzner, R., \& Johnson, S. S. (1997). Seeing things as they really are. Forbes, 159(5), 122129. 
Lister, C. (2014). Changing role of the teacher in the dijital age. http://christopherlister.ca/tiegrad-2/the-changing-role-of-the-teacher-in-the-digital-age/

26.12. 2016 tarihinde erişilmiştir.

Longworth, N. (2003). Lifelong learning in action: Transforming education in the 21st century. Routledge.

Jenkins, H., Purushotma, R., Weigel, M., Clinton, K., \& Robison, A. J. (2009). Confronting the challenges of participatory culture: Media education for the 21st century. Mit Press.

Margaryan, A., Littlejohn, A., \& Vojt, G. (2011). Are digital natives a myth or reality? University students' use of digital technologies. Computers \& Education, 56(2), 429440.

Njenga, J. K., \& Fourie, L. C. H. (2010). The myths about e-learning in higher education. British journal of educational technology, 41(2), 199-212.

Prensky, M. (2001). Digital natives, digital immigrants: do they really think differently? On the Horizon, 9(6), 1-6.

Richardson, W. (2012). Why school? How education must change when learning and information are everywhere. New York, NY: TED Books.

Robert Lenzner \& Stephen S. Johnson. (1997). Seeing things as they really are. Forbes. http://www.forbes.com/forbes/97/0310/5905122a.htm\#DRUC. 24. 12.2016 tarihinde erişilmiştir.

Spada, K. (2014). Higher Education in the Digital Age [Book Review]. IEEE Transactions on Professional Communication, 57(2), 150-153.

Tamer, M. G. (2014). Yaşam boyu öğrenme için ulusal yeterlilikler çerçevesi: Avrupa ve Türkiye örneği. International Journal of Curriculum and Instructional Studies, 3(5).

Thiele, A. K., Mai, J. A., \& Post, S. (2014). The student-centered classroom of the 21 st century: Integrating web 2.0 applications and other technology to actively engage students. Journal of Physical Therapy Education, 28(1), 80.

Toffler, A. C. (1971). Learning to Live with Future Shock. College and University Business, 51(3), 55-7.

Veletsianos, G. (2010). Emerging technologies in distance education. Athabasca University Press. 


\section{Yazar Hakkında}

\section{Okutman Eylem KORAL GÜMÜŞOĞLU}

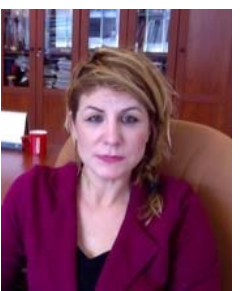

Eylem Koral Gümüş̧oğlu Anadolu Üniversitesi Yabancı Diller Yüksekokulunda İngilizce okutmanı olarak görev yapmaktadır. Lisans eğitimini Orta Doğu Teknik Üniversitesi Yabancı Diller Eğitimi Bölümünde 2000 yılında tamamlamıştır. 2003 yılında Fullbright bursu ile Bilkent Üniversitesi Yabancı Dil Olarak İngilizce Öğretimi Üzerine (MATEFL) ile yüksek lisans yapmıştır. Daha sonra yazar 2000 yılında yine Fullbright bursu aracılığı ile Yabancı Dil Öğretimi Asistanı (FLTA) olarak Şikago, Amerika'da bulunan Governors State Universitesi'nde 1 yıl boyunca çalışmıştır. Eylem Koral Gümüşoğlu 2014 yılından beri Sosyal Bilimle Enstitüsü Uzaktan Eğitim Ana Bilim Dalında doktora öğrencisidir. Yazarın araştırma konuları arasında sosyal ağlar, arttırılmış gerçeklik, e -öğrenme, bilgi ve eğitim teknolojileri bulunmaktadır.

Posta adresi: Anadolu Üniversitesi Yabancı Diller Yüksekokulu, 2 Eylül Kampüsü,Eskişehir,Türkiye, 26470 Tel (İş): $\quad$ +90 3350580/6170

Eposta: $\quad \underline{\text { ekoral@anadolu.edu.tr }}$ 